$\begin{array}{ll} & \text { Etnográfica } \\ \text { etnográfica } & \text { Revista do Centro em Rede de Investigação em }\end{array}$

Antropologia

vol. $13(1) \mid 2009$

Vol. $13(1)$

\title{
Secularização e espaço público: a reinvenção do pluralismo religioso no Brasil
}

Secularization and public space: the re-invention of religious pluralism in Brazil

\section{Paula Montero}

\section{(2) OpenEdition}

\section{Journals}

\section{Edição electrónica}

URL: https://journals.openedition.org/etnografica/1195

DOI: 10.4000/etnografica. 1195

ISSN: 2182-2891

\section{Editora}

Centro em Rede de Investigação em Antropologia

\section{Edição impressa}

Data de publição: 2 maio 2009

Paginação: 7-16

ISSN: 0873-6561

\section{Refêrencia eletrónica}

Paula Montero, «Secularização e espaço público: a reinvenção do pluralismo religioso no Brasil», Etnográfica [Online], vol. 13 (1) | 2009, posto online no dia 16 março 2012, consultado o 10 fevereiro 2022. URL: http://journals.openedition.org/etnografica/1195 ; DOI: https://doi.org/10.4000/ etnografica. 1195

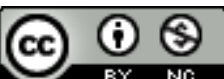

Etnográfica is licensed under a Creative Commons Attribution-NonCommercial 4.0 International License. 


\title{
Secularização e espaço público: a reinvenção do pluralismo religioso no Brasil
}

\begin{abstract}
Paula Montero
Este texto examina as particularidades do processo de emergência do espaço público no Brasil e seu impacto sobre o campo religioso. Desafiando o paradigma da secularização, nosso argumento procura demonstrar que a religião católica operou como modelo e referência para a formulação de direitos e enquadramento das práticas populares enquanto práticas religiosas. O pluralismo religioso brasileiro seria, pois, decorrente de um processo histórico de controvérsias sobre práticas de cura, de feitiçaria e de possessão que implicou na "invenção" de novas religiões.

PALAVRAS-CHAVE: espaço público, religiões populares, secularização, pluralismo religioso.
\end{abstract}

GRANDE PARTE DA LITERATURA SÓCIO-ANTROPOLÓGICA CONTEMPORÂNEA tem tratado o problema da presença das religiões no espaço público em termos da metáfora do "mercado". Tomando como referência a imagem de que a esfera pública funcionaria como um palco no qual atores e coisas disputam a sedução dos consumidores, a possibilidade de sucesso de uma religião dependeria de sua capacidade de tornar-se espetáculo e de chamar atenção da mídia. Experiências televisivas como as do pentecostalismo e neopentecostalismo nos anos 1980 e dos carismáticos na década subseqüente perturbam os observadores da cena religiosa e inquietam os que não conseguem mais reconhecer nesses movimentos de massa as formas religiosas tradicionais. Os mais pessimistas lamentam a dessacralização do religioso, os otimistas procuram ver nessa espetacularização do fervor um sinal do revigoramento dos sentimentos religiosos e um antídoto contra o materialismo contemporâneo.

Não se trata aqui de tomarmos partido nesse debate mas, sim, de refletirmos sobre os a priori implícitos que organizam os termos de sua formulação. 
Ao conceber a esfera pública em termos de mercado esse debate parte do suposto normativo implícito de que a religião está "fora de seu lugar" - isto é, está invadindo a esfera pública que deveria ser autônoma com relação às crenças - e, em conseqüência disso, está tornando-se ela mesma mercadoria, ao assumir uma lógica própria aos espaços profanos de consumo de massa. Ao invés de restringirem-se ao mundo da vida privada, as instituições religiosas penetram de maneira cada vez mais acintosa na indústria do entretenimento, tornando-se proprietárias de canais de televisão e de emissoras de rádio, alimentando o mercado musical e do turismo, e se movem com autonomia crescente no campo das políticas públicas, promovendo campanhas nos setores da educação, da saúde e do trabalho. A natureza dessas "impertinentes" derivações do domínio religioso para além das fronteiras que lhe foram designadas como próprias pelo modelo secular republicano ainda não foi bem estudada em sua forma, estrutura e dimensões.

Gostaríamos de propor neste ensaio que se o problema teórico das relações entre religiões e esfera pública reiteradamente se desloca para o domínio do normativo é porque o campo da sociologia/antropologia da religião ainda não conseguiu libertar-se das determinações éticas implícitas no paradigma weberiano da secularização. Como se sabe, esse paradigma supõe que, no processo histórico de construção da modernidade, o Estado se tornaria cada vez menos acessível aos processos de moralização e a religião, desprovida de suas funções integradoras do passado, se deslocaria para o mundo privado, assentando sua plausibilidade não mais no poder político mas nas consciências individuais. Ora, a nosso ver, pensar o nascimento de uma esfera civil secular em termos de processos de "secularização", isto é, de autonomia interior do indivíduo, é introduzir nos instrumentos de análise o legado protestante que deduz a emergência histórica da esfera social da lógica racionalizadora inerente ao próprio protestantismo.

Muitos críticos já demonstraram que esse paradigma está implicitamente apoiado em um suposto teleológico da história que entende a modernização de uma sociedade como um duplo processo que deve necessariamente vir acompanhado, por um lado, do deslocamento do religioso para o mundo privado e, por outro, da proposição de um sentido ético que oriente o agir no mundo político e econômico (Casanova 1994; Pierucci 2000; Montero 2003; Gasbarro 2004). Além disso, o conceito de "secularização", tal como proposto por Max Weber, supõe que as religiões de salvação, enquanto motor dos processos de modernização, se tornam, elas mesmas, cada vez mais racionalizadas e subjetivadas, deixando para trás a dimensão mágica que as caracterizou historicamente.

Ora, quando se observa, mesmo superficialmente, o cenário brasileiro, percebe-se rapidamente que o modo como as religiões se expandiram no espaço público não correspondeu a essa fórmula. A dimensão que a literatura definiu como "mágica", isto é, irracional e emocional, por oposição ao que se concebeu 
como "crenças religiosas", não apenas não declinou como estimulou a criação já no final do século XX de "novos movimentos religiosos" que ampliaram a noção mesma de campo religioso para novas dimensões da vida social. Além disso, longe de "privatizar-se", as religiões, desde sempre, imiscuíram-se das mais variadas formas na construção e na gestão do espaço público. A presença histórica das igrejas cristãs nas áreas de educação, saúde, assistência social, etc. correspondeu a uma delegação consentida e pactuada pelo próprio Estado. A concessão pública de canais televisivos e de radiodifusão a confissões religiosas tampouco é um fenômeno recente. No campo da política também já nos habituámos à presença de bancadas religiosas no Congresso.

Todas essas formas de visibilidade e agenciamento público das religiões também se manifestam no campo da linguagem política, ora re-significando suas principais categorias, tais como igualdade e direito, ora introduzindo no debate valores religiosos como fundamento para a produção de consenso em torno de certas opiniões, ora mobilizando grupos sociais em torno de determinadas causas. Alguns exemplos mais conhecidos desse fenômeno relatados pelos estudiosos dizem respeito, no caso católico, ao modo como o discurso teológico da libertação imantou de paixão religiosa as categorias de "participação" e de "comunidade" e, no caso protestante, como a "teologia da prosperidade" produziu uma idéia de "direito" dissociada do conceito de cidadania, que nas teorias da democracia é concebida como diretamente ligada aos direitos de propriedade e de acesso aos bens e aos direitos de participação política. No caso dos neopentecostais, através das formulações da "teologia da prosperidade", a noção de acesso aos bens articulou-se, paradoxalmente, não à lógica do mercado, mas à do dom e contra-dom tão bem estudada pela antropologia. Com efeito, nas práticas discursivas neopentecostais todo indivíduo deve exercer seu "direito à prosperidade", formulação esta que enuncia de modo bastante particular a idéia de "inclusão social" e de "ordem legal" posto que não passa, como no caso do discurso católico, pela noção de fraternidade ou de comunidade.

Os exemplos rapidamente relatados acima para ilustrar a complexidade das relações entre religiões e espaço público nos permitem sugerir a hipótese da insuficiência teórica da noção weberiana de "secularização" para pensar os fenômenos da publicização das religiões na cena contemporânea, ou ainda para compreender como, em contraposição à Igreja católica tida como referência, as outras religiões lutam pela legitimidade de sua "ação social". Penso que é possível propor essa relação de modo menos normativo: a secularização não precisa ser postulada como condição sine qua non da emergência de uma esfera pública democrática. Ou, dito de outro modo, o conceito de "secularização" talvez tenha deixado de ser útil como categoria analítica, tendo-se deslocado, progressivamente, para a esfera normativa.

Isto não significa que estamos em desacordo com Max Weber quando o autor afirma, em sua teoria geral da secularização, que a emancipação histórica 
da esfera secular do domínio do religioso teria sido um processo inerente à modernização das sociedades que culminou, como sabemos, com a separação jurídica entre Estado e Igreja. No entanto, mais do que reiterar a necessidade abstrata dessa separação para que a modernização tenha lugar, parece-me ser interessante e profícuo observar como cada processo histórico particular produziu esse tipo de ruptura, de modo a compreender como uma sociedade específica configura para si aquilo que ela entende como esfera civil.

Autores como Jünger Habermas (2003 [1961]) nos mostraram que é possível dispensar o paradigma da secularização para analisar os processos históricos particulares da emergência das distintas esferas - política, social, econômica, religiosa, etc. - e, consequentemente, para pensar a emergência dessa distinção entre esfera pública e esfera privada que se tornou tão essencial à nossa concepção de ordem social.

Se considerarmos essa distinção habermasiana entre Estado/sociedade civil/esfera privada como fundadora de nossa modernidade, tal como sugere este autor, e a partir dela voltarmos nosso olhar para o modo como essa diferenciação se produziu historicamente no Brasil na passagem do século XIX para o século XX, poderemos, a nosso ver, colocar em um novo patamar o debate sobre as relações entre o espaço público e a religião.

Partiria da hipótese inicial de que, ao contrário do que aconteceu na Europa, particularmente na França, onde o pluralismo religioso emerge como valor político a partir de uma longa história de guerras religiosas e movimentos cismáticos que desafiavam a correspondência entre unidade política e unidade religiosa, ${ }^{1}$ no Brasil o próprio processo de separação Igreja/Estado teve como produto histórico a produção de novas religiões. Se a "liberdade religiosa", compreendida como liberdade de consciência, foi cronologicamente a primeira liberdade, isto é, condição de todas as outras, como sugere Casanova (1994), o "pluralismo religioso" no Brasil não resultou da conflituosa convivência de diversas confissões religiosas preexistentes à constituição do Estado republicano - em particular o catolicismo, as "seitas" protestantes e os judeus, como no caso francês - cuja presença pública e direitos civis o Estado pretendeu regular. O pluralismo religioso no Brasil, isto é, o reconhecimento legal da diversidade de cultos e a garantia de liberdade religiosa, foi o resultado de um longo debate político-científico em torno daquilo que o Estado (e a sociedade) podiam legitimamente reconhecer e aceitar como "prática religiosa".

Se examinarmos o caminho particular que o Estado brasileiro tomou para se constituir enquanto Estado republicano, que exigiu a constituição de uma esfera secular distinta da autoridade religiosa, podemos distinguir dois processos paralelos: de um lado, travou-se um debate jurídico para a delimitação dos direitos de propriedade da Igreja católica e pela redefinição de seu papel 
político e econômico; de outro, desenvolveu-se uma longa controvérsia, que envolveu médicos, juristas, jornalistas, quadros da Igreja católica e outros intelectuais, para estabelecer um consenso a respeito da legitimidade de certas práticas populares, percebidas como mágicas e supersticiosas e associadas a atos de feitiçaria e possessão. Tratava-se de definir se elas deveriam ou não ser objeto da repressão do Estado em nome da "ordem pública", concebida naquele momento em termos do quadro científico proposto pelo higienismo. Naquele momento, era uma auto-evidência amplamente compartilhada considerar que a "religião", isto é, esse sistema ordenado de um corpus doutrinário e litúrgico abstrato que diz respeito às relações dos homens com o mundo do transcendente, era apenas a religião católica. O estatuto dessas outras práticas, que evidentemente não cabiam nesse modelo, foi objeto de controvérsias médico-legais que perduraram por mais de meio século.

Tendo como ponto de partida esse contexto histórico, podemos agora nos perguntar: a partir de quais critérios, em um determinado momento histórico, se reconhece um conjunto de práticas como "religiosas" ou, em uma formulação mais antropológica, onde, quando, como e pelas mãos de quem um sistema de classificações se move para tornar certas práticas legítimas e aptas a serem incluídas naquilo que uma sociedade entende como "religião"?

A literatura a esse respeito nos mostra que desde o primeiro momento da República o combate à feitiçaria e ao curandeirismo fizeram parte do processo de constituição do que era então concebido como "ordem pública" urbana. ${ }^{2}$ A remodelação urbana que foi empreendida no Rio de Janeiro no início do século XX sob a batuta do sanitarista Oswaldo Cruz exigiu uma ampla mudança de hábitos da população urbana pobre, mediante uma rigorosa legislação que proibia venda de miúdos e ordenha de vacas no passeio público, bem como urinar e cuspir nas ruas. Data desse período (1902-1904) uma estrita vigilância sobre as condições de higiene das famílias e a criminalização das práticas de cura irregulares. É nesse contexto que se produz a figura jurídica do "charlatanismo".

O grande problema para a "ordem pública" republicana era transformar as práticas cotidianas de negros e mestiços de modo a constituir uma ordem civil fundada nos "bons costumes" e capaz de apresentar-se como civilizada e moderna. Mas, para que isso pudesse ser empreendido como política pública, era preciso acumular conhecimento antropológico, psiquiátrico e legal que permitisse aos agentes governamentais distinguirem o "feiticeiro" do "charlatão", o "curandeiro" do "explorador da credulidade pública". Tendo em vista que o modus operandi do código legal supõe a existência de um indivíduo imputável e que o transgressor é aquele que age com consciência da improbidade dos atos praticados, era necessário dar a legislador e juízes instrumentos para que 
pudessem distinguir a "verdadeira crença" nos atos mágicos de cura - ainda que crédula ou supersticiosa, isto é, desvirtuada por excesso de crença - da "manipulação" cínica da crença para benefício próprio, denominada de "charlatanismo". Muitas vezes o critério utilizado para estabelecer esse sistema de diferenças foi formulado em termos da oposição caridade/interesse retirada, evidentemente, do repertório moral católico; a investigação a respeito da presença ou ausência de benefícios materiais associados a esses atos foi, frequentemente, utilizada como instrumento de medida para avaliar o grau de perversidade dessas práticas.

Assim, se, como dissemos anteriormente, a "liberdade religiosa", entendida como "liberdade de consciência", serviu de modelo para a definição dos direitos civis, a constitucionalidade jurídica da República se viu obrigada a enfrentar as dificuldades de distinguir as práticas de cura tidas como "mágicas", que deveriam ser criminalizadas como exercício ilegal da medicina, das práticas "verdadeiramente religiosas", fundadas em convicções genuínas a respeito dos seres espirituais.

Vemos a partir destes exemplos que a referência inconsciente utilizada pelo Estado e seus agentes para definir o direito de certas práticas sociais tinha como modelo a idéia de "religião" instituída historicamente pelo catolicismo e, posteriormente, intermediada por uma grande variedade de outras práticas. Com efeito, se voltarmos nosso olhar para o programa político instituído pelo regime republicano para laicizar o Estado e excluir os critérios religiosos da definição de cidadania, veremos que, ao contrário do código penal, ele não se ocupou em regular essas práticas. Os atos jurídicos instituídos pela normatividade do novo código civil trataram de separar os atos civis (nascimento, casamento, educação, saúde, etc.) dos efeitos civis anteriormente gerados pelos sacramentos cristãos (batismo, matrimônio, extrema-unção). Ao mesmo tempo, foi necessário redefinir também os direitos da Igreja católica quanto ao usufruto e propriedade de seus bens, quanto à isenção de impostos e direitos a doações.

Pode-se dizer portanto que, excetuando-se o reconhecimento de uma presença minoritária (e competidora) de protestantes, durante um longo período a sociedade brasileira não formulou a idéia da existência de uma diversidade de religiões no país. Ainda que a constituição republicana tenha proibido ao Estado interferir na religião e tenha garantido a liberdade de culto, a repressão às práticas tidas como "mágicas" (e portanto, não religiosas) perdurou até meados do século passado. Durante meio século práticas de cura, danças, tambores, reuniões de possessão, sacrifícios de animais enfrentaram a ordem repressiva do Estado, ora porque desafiavam a moralidade pública, ora porque perturbavam o sossego das famílias, ora porque levavam à histeria e outras doenças, ora porque eram simples expressão de incivilidade e "barbárie". Ao mesmo tempo, no mesmo período e por diversas razões que não cabe aqui retomar, médicos, 
advogados, intelectuais e líderes de toda sorte tentavam demonstrar que essas práticas não representavam uma ameaça à ordem e à saúde pública porque, na verdade, deviam ser entendidas como práticas religiosas.

Assim, embora os gabinetes clínicos e as farmácias populares espíritas não tivessem, em um primeiro momento, a pretensão de fazer-se reconhecer no campo religioso, a alternativa jurídica que lhes restou para defender-se nos tribunais foi argumentar que a "mediunidade" ou a "psicografia" eram, na verdade, um rito religioso. No mesmo movimento, antropólogos e outros estudiosos buscaram destituir o caráter patológico e transgressor da "possessão" marcada historicamente pela revolta do negro, patologizada, criminalizada e combatida pela Igreja católica como prática de feitiçaria. No contexto intelectual e cientificista da primeira metade do século XX era mais fácil admitir a legitimidade da "mediunidade", que podia ser lida como um processo biológico universal de alteração da consciência, do que admitir a respeitabilidade da "possessão", noção ainda muito próxima da heresia diabólica.

A partir desse rápido panorama histórico podemos concluir que o próprio processo de repressão a essas práticas consideradas "selvagens" e antinômicas à ordem pública contribuiu para que elas fossem progressivamente assumindo a forma legítima de "religião", de modo a constituir o "pluralismo religioso" tal como ele se apresenta hoje na cena pública brasileira. Vejamos agora como esse processo se relaciona ao tema que aqui nos interessa: a relação entre as religiões e o espaço público.

Se levarmos em conta esse processo histórico aqui esboçado em suas grandes linhas, é possível afirmar que a noção de "pluralismo religioso" no Brasil não é uma categoria política que resulta de um processo de luta pelo reconhecimento de uma convicção religiosa; trata-se mais bem de uma categoria sociológica para descrever a resultante histórica de um processo de ordenação e codificação de práticas em sistemas religiosos. O debate jurídico/político sobre a liberdade de culto ocupou-se prioritariamente, no momento de sua formulação, em dissociar a comunidade de culto da comunidade política. No entanto, é interessante observar que, embora o princípio de liberdade religiosa tenha se institucionalizado juridicamente, a "Igreja" - isto é, esse tipo particular de maquinaria burocrático-legal associado ao Estado que garante o monopólio estatal da crença - mantém seu poder político de natureza estatal, resistindo a tornar-se uma "comunidade de culto" entre outras. Embora tenha aceitado o princípio legal da separação do Estado, por um longo período conseguiu garantir a identificação simbólica e política entre comunidade política e comunidade de culto, produzindo uma convicção, bem enraizada na longa duração, a respeito da equivalência entre sociedade brasileira e religião católica.

Eu diria que, embora tendo perdido hoje sua folgada hegemonia, o fato de ser a única instituição que pode apresentar-se publicamente como "Igreja" indica que essa associação se mantém no imaginário político. Se isso é verdade, 
diríamos que a esfera pública brasileira se forja historicamente deixando em baixo-relevo a marca invisível da civis cristã. Ao lançar o catolicismo para o espaço social ele se torna a matriz da distinção Estado/mundo civil/mundo privado. No mesmo movimento, forja a linguagem do que pode ser dito e pensado legitimamente nesse espaço, definindo os modos aceitáveis de dizer e aparecer, as formas legítimas de reivindicar direitos. A demonstração da pervasividade dessa matriz como linguagem aceitável na esfera pública está no fato, por exemplo, de que o direito a ter "igrejas" sobre as vias públicas ainda é prioritariamente católico (ainda que algumas denominações protestantes disputem esse privilégio e se apresentem como "templos"). As denominações do tipo neopentecostal ocupam o espaço metropolitano através de edificações públicas de outros tipos, tais como cinemas e teatros, e as outras práticas religiosas deslocadas simbolicamente para uma forma de representação do espaço menos pública se autodenominam casas, terreiros, tendas, associações, centros, etc.

Além disso, grande parte das categorias utilizadas na mobilização política e seus estilos de organização também podem ser consideradas tributárias do modelo de organização da Igreja católica que, a partir dos anos 1970, inspirou e apoiou vários movimentos que deram origem e visibilidade ao que a literatura alcunhou de "sociedade civil". Basta observar como categorias do tipo "pobre", "comunidade", "caminhada", "libertação", "fraternidade", etc. circulam no campo dos movimentos sociais para nos darmos conta da força persuasiva desse modelo. Como sugere André Corten (1996), a própria idéia de "participação" que marcou o cenário da mobilização da sociedade civil a partir dos anos 1970 é uma categoria que pertence ao discurso teológico. Segundo ele, o discurso teológico é uma forma discursiva que se caracteriza pela produção de um "efeito de piedade". Esse efeito se produz através de uma narrativa profética que vê signos de Deus nos eventos e assim fala à imaginação produzindo a "participação". O "efeito de piedade" constitui como base da ação coletiva um tipo particular de imagem do Sujeito político - ele se apresenta como o "povo de Deus". Assim, conclui Corten, o que as Comunidades Eclesiais de Base, por exemplo, procuraram fazer foi injetar no discurso político a "mobilização participativa" advinda do discurso profético, tomando como suporte da ação uma representação teológica da política que a interpreta, não como "pacto social", mas como signo da aliança com Deus.

Esses exemplos demonstram que há uma desigualdade estrutural, histórica, na percepção que se tem a respeito da legitimidade da ação das diferentes religiões na esfera pública. O catolicismo ainda mantém, a meu ver, a primazia simbólica e política na passagem dos valores para as normas. Mas, por outro lado, o sistema jurídico republicano, ao não ter reconhecido, como vimos, a institucionalização das práticas não cristãs como "religiões", deslocou essas práticas para o campo das associações civis filantrópicas. Desse modo, paradoxalmente, a atividade "religiosa" se espalhou pelo tecido social, tornando-se 
indistinguível das práticas propriamente civis de filantropia e assistência. A religiosidade enquanto "ação social" pode incorporar-se ao tecido da esfera pública disputando com outras linguagens, tais como turismo, arte, cultura, a distribuição dos recursos e concessões públicas. Ora, sabemos bem que no Brasil a gramática da "caridade" se mantém viva como princípio de legitimação das ações públicas. A caridade, virtude teologal que conduz a Deus e aos pobres, representa a imagem especular reversa da feitiçaria - ato egoísta e pecuniário que opera na lógica do dom e contra-dom. Terá sido talvez em razão dessa anastrofia que o código da feitiçaria não teve a mesma capacidade de produção do consenso sobre sua legitimidade no espaço público do que o código da caridade: este supõe, como sabemos, uma igualdade abstrata entre irmãos e a idéia de "compaixão", ou seja, sistema de dom que não supõe, pelo menos de modo consciente, a contraprestação. Já a lógica da feitiçaria constitui um sistema de acusações cuja dinâmica só pode ser neutralizada através da operacionalização de complexos mecanismos de compensação. A idéia de "caridade" foi apropriada e re-significada por diferentes práticas religiosas. Em seu processo de legitimação social o espiritismo, por exemplo, lançou mão da noção de "caridade" associando-a a uma interpretação própria de "cidadania". Segundo a leitura proposta por Giumbelli (1997), o espiritismo articulou a prática da "caridade" à idéia de "assistência social", tornando o "pobre" não mais objeto de doação ou esmola mas "sujeito de direitos". Vemos pois que através desses processos de re-significação da idéia de caridade a atividade religiosa se expande para o campo da assistência social. Essas observações nos permitem argumentar que, nos processos de legitimação das políticas de "ação social”, a linguagem religiosa é fundamental. A linguagem abstrata do Estado não percola o tecido social, nem conquista parcela importante de corações e mentes sem a intermediação dos agentes religiosos e sua gramática comunitária.

Talvez possamos sugerir, à guisa de conclusão, que se há alguma mutação em andamento no campo da disputa pela legitimidade política de certas categorias religiosas ela vem se desenhando pela via do neopentecostalismo, em particular pelas práticas discursivas da Igreja Universal do Reino de Deus, sob o comando do bispo Edir Macedo. Principal representante da "teologia da prosperidade" norte-americana no Brasil, esse discurso reabilita o dinheiro e a "vida em abundância" como principais códigos religiosos e desqualifica o "pobre" como o sujeito e objeto da ação política. É muito difícil antecipar como e se as controvérsias que ela suscita, ao disputar ao mesmo tempo a hegemonia católica no campo da "verdadeira religião" e a eficácia simbólica afro no campo da "magia", terão algum impacto na reconfiguração dos processos que dão legitimidade política às categorias religiosas. À sombra da teologia da libertação a Igreja católica imprimiu uma certa formulação ao que deve ser entendido como ação social e ao que pode ser percebido como legítimo quando agentes 
religiosos ganham visibilidade no espaço público. Mas a idéia de "comunidade de base" que dava sustentação e verosimilhança à síntese entre comunidade de culto e comunidade política perdeu sua magia. Se o emblema do "povo de Deus" não é mais persuasivo no plano da imaginação política, resta saber se a utopia da "vida em abundância" dará forma a algum tipo de comunidade imaginária que vá além da fronteira dos conversos para constituir uma rede de mediações mais universais que possa figurar de modo aceitável e plausível como comunidade política.

\section{BIBLIOGRAFIA}

CASANOVA, José, 1994, Public Religions in the Modern World. Chicago, The University of Chicago Press.

CORTen, André, 1996, Os Pobres e o Espírito Santo: O Pentecostalismo no Brasil. Petrópolis, Vozes.

GASBARRO, Nicola, 2004, "Il concetto di 'religione' come problema antropológico: genesi e sviluppo". Policopiado.

GIUMBELLI, Emerson, 1997, O Cuidado com os Mortos: Uma História da Condenação e da Legitimação do Espiritismo. Rio de Janeiro, Arquivo Nacional

—, 2000, O Fim da Religião: Controvérsias acerca das "Seitas" e da "Liberdade Religiosa" no Brasil e na França. Rio de Janeiro, Museu Nacional, tese de doutoramento.

HABERMAS, Jünger, 2003 [1961], Mudança Estrutural na Esfera Pública. Rio de Janeiro, Tempo Brasileiro.

MONTERO, Paula, 2003, "Max Weber e os dilemas da secularização: o lugar da religião no mundo contemporâneo". Novos Estudos Cebrap, 65: 34-44.

—, 2006, "Religião, pluralismo e esfera pública no Brasil”, Novos Estudos Cebrap, 74: 47$-65$.

PIERUCCI, Flávio, 2000, “A secularização segundo Max Weber", em Jessé de Souza (org.), A Atualidade de Max Weber. Brasília, Universidade de Brasília, 105-162.

Secularization and public space: the re-invention of religious pluralism in Brazil - Paula Montero • Universidade de São Paulo; CEBRAP • pmontero@usp.br

This essay analyses the historical process of secularization in Brazilian post-Republic period. Comparing with the emergency of republicanism in France this article stresses the particularities in the Brazilian development of a civil public space. Taking into account ethnographic examples of popular religions the analysis confronts the Weberian paradigm of secularization. 